Supplement of Earth Surf. Dynam., 8, 123-159, 2020

https://doi.org/10.5194/esurf-8-123-2020-supplement

(C) Author(s) 2020. This work is distributed under

the Creative Commons Attribution 4.0 License.

(c) (1)

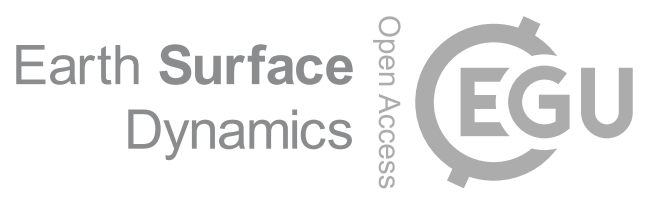

Supplement of

\title{
Geomorphic signatures of the transient fluvial response to tilting
}

Helen W. Beeson and Scott W. McCoy

Correspondence to: Helen W. Beeson (hbeeson@nevada.unr.edu)

The copyright of individual parts of the supplement might differ from the CC BY 4.0 License. 
(a)
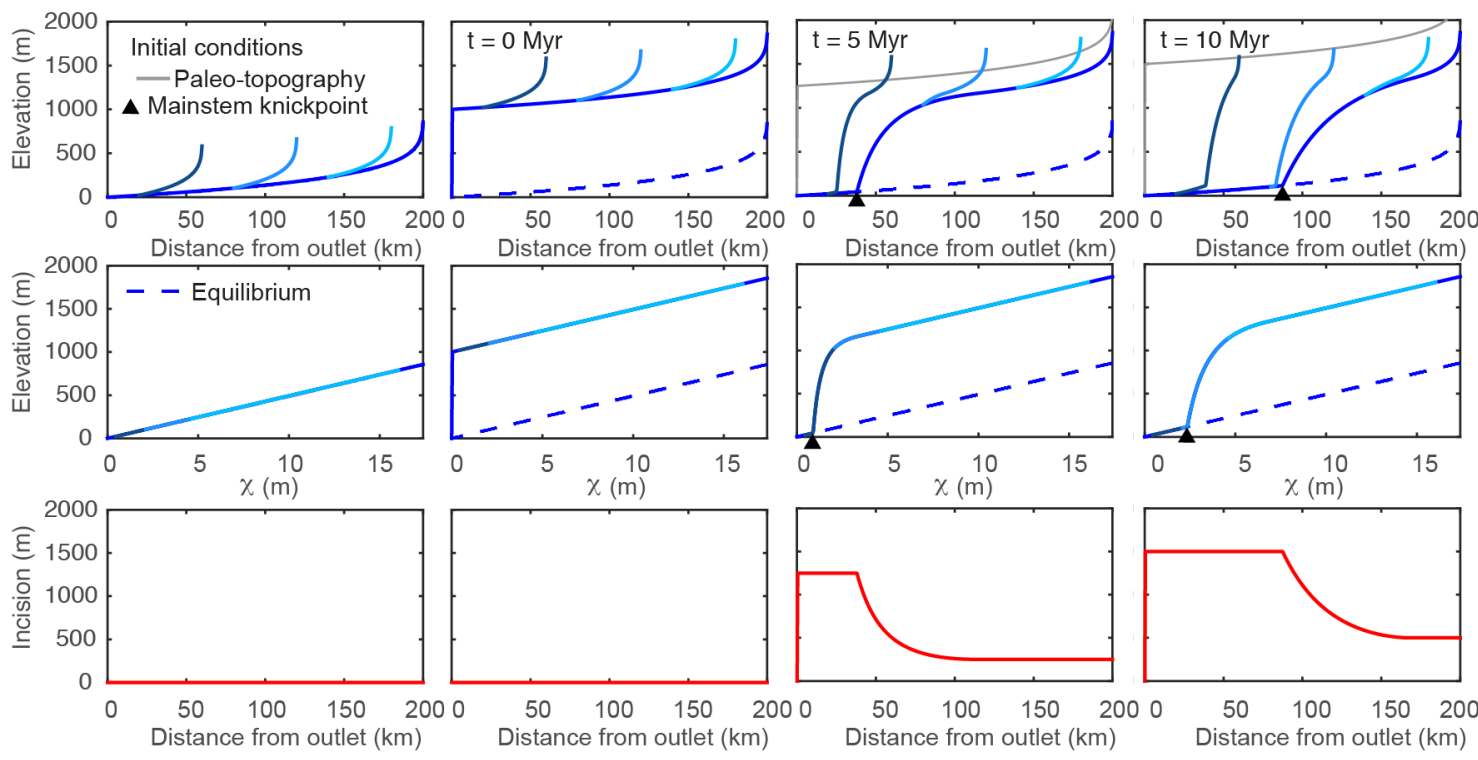

(b)

Instantaneous increase in erodibility at $\mathrm{t}=0 \mathrm{Myr}$. Steady uniform background uplift rate of $50 \mathrm{mMyr}^{-1} . n=2 / 3$.
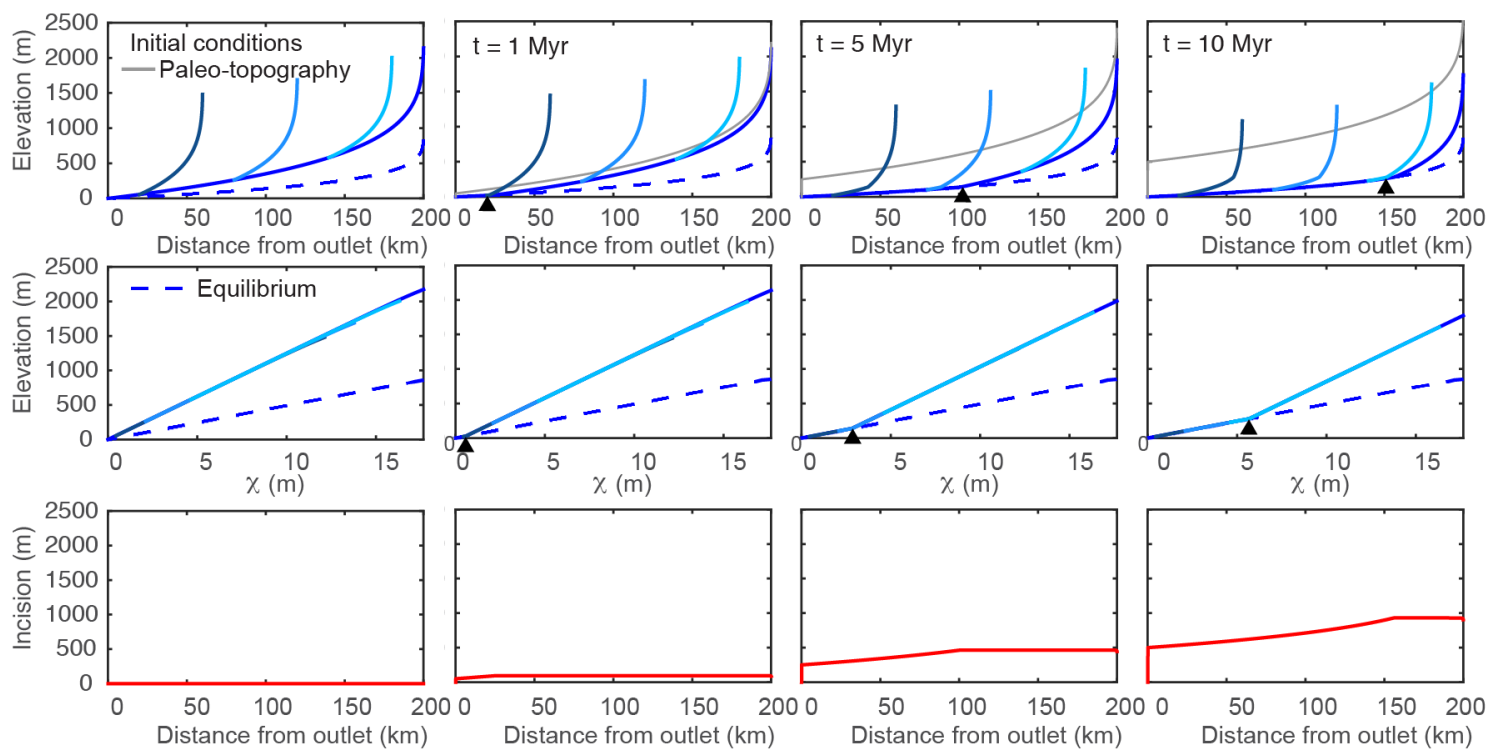

Figure S1. Results from 1-D simulations of equilibrated river network subject to various perturbations that move profiles away from equilibrium. Simulations are analogous to those presented in Fig. 2 but were run with $n=2 / 3$. We used the same concavity, $\theta=0.45$, as other simulations but adjusted $K$ to $3.7 \times 10^{-6} \mathrm{~m}^{0.4} \mathrm{yr}^{-1}$ such that steady-state fluvial relief remained the same between all simulations run with $n=1$ and $n=2 / 3$. Results from multiple timesteps for simulation of instantaneous uniform uplift of: $1 \mathrm{~km}$ at $t=0 \mathrm{Myr}$ (a); step increase in erodibility, $K$, or equivalently a step decrease in rock uplift rate (b). Line color, basic description of plots filling each row, and network structure are the same as described in Fig. 1. 
(a)

Instantaneous uniform uplift of $1 \mathrm{~km}$ at $\mathrm{t}=0$ Myr. Steady uniform background uplift rate of $50 \mathrm{mMyr}^{-1} . n=5 / 3$.
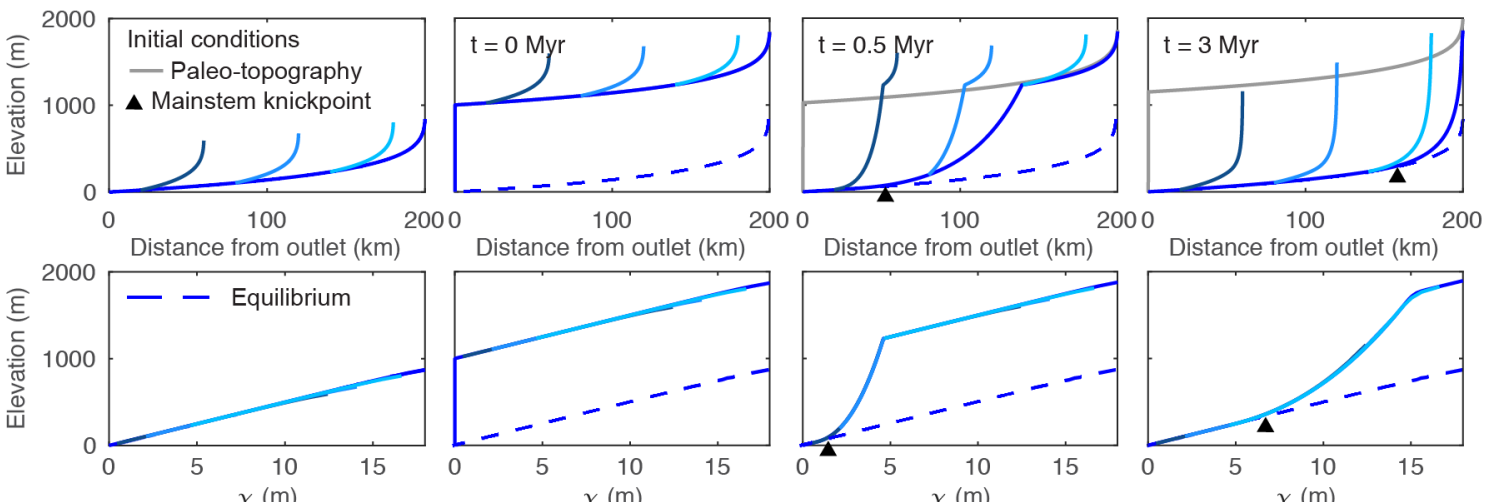

Distance from outlet $(\mathrm{km})$
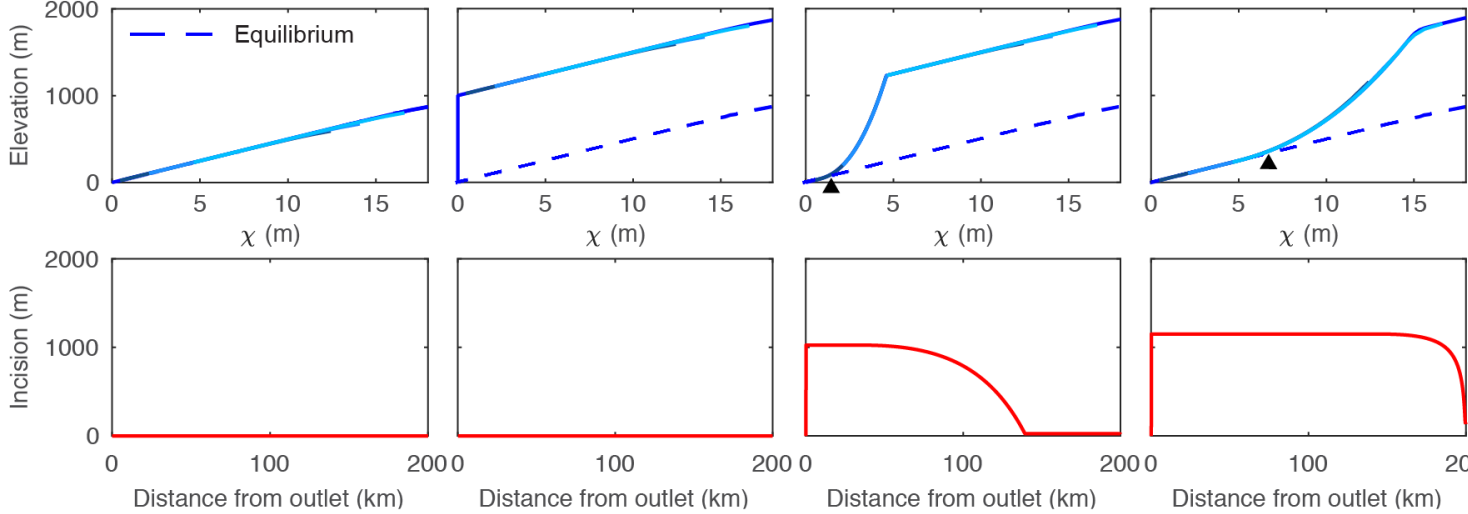

(b)

Instantaneous increase in erodibility at $\mathrm{t}=0 \mathrm{Myr}$. Steady uniform background uplift rate of $50 \mathrm{mMyr}^{-1} . n=5 / 3$.
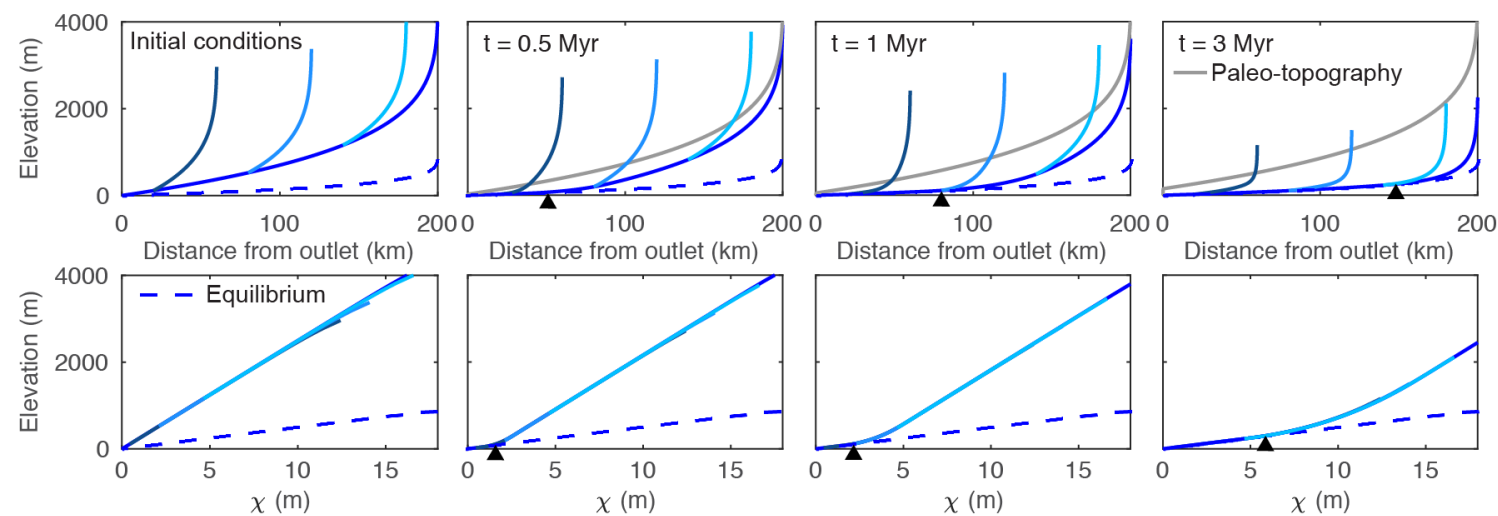

Distance from outlet $(\mathrm{km})$
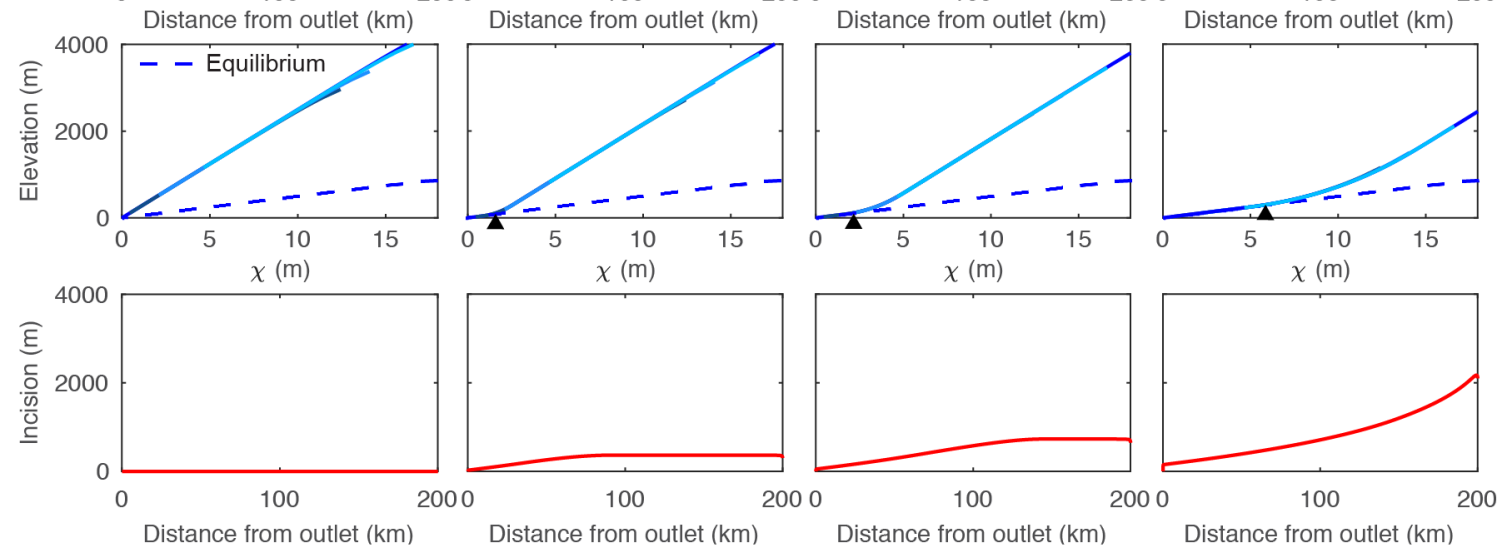

Figure S2. Results from 1-D simulations of equilibrated river network subject to various perturbations that move profiles away from equilibrium. Simulations are analogous to those presented in Fig. 2 but were run with $n=5 / 3$. We used the same concavity, $\theta=0.45$, as other simulations but adjusted $K$ to $7.4 \times 10^{-8} \mathrm{~m}^{-0.5} \mathrm{yr}^{-1}$ such that steady-state fluvial relief remained the same between all simulations run with $n=1$ and $n=5 / 3$. Results from multiple timesteps for simulation of instantaneous uniform uplift of: $1 \mathrm{~km}$ at $\mathrm{t}=0 \mathrm{Myr}(\mathbf{a})$; step increase in erodibility, $K(\mathbf{b})$. Line color, basic description of plots filling each row, and network structure are the same as described in Fig. 1. 
Instantaneous decrease in erodibility at t $=0$ Myr. Steady uniform background uplift rate of $50 \mathrm{mMyr}^{-1}$.
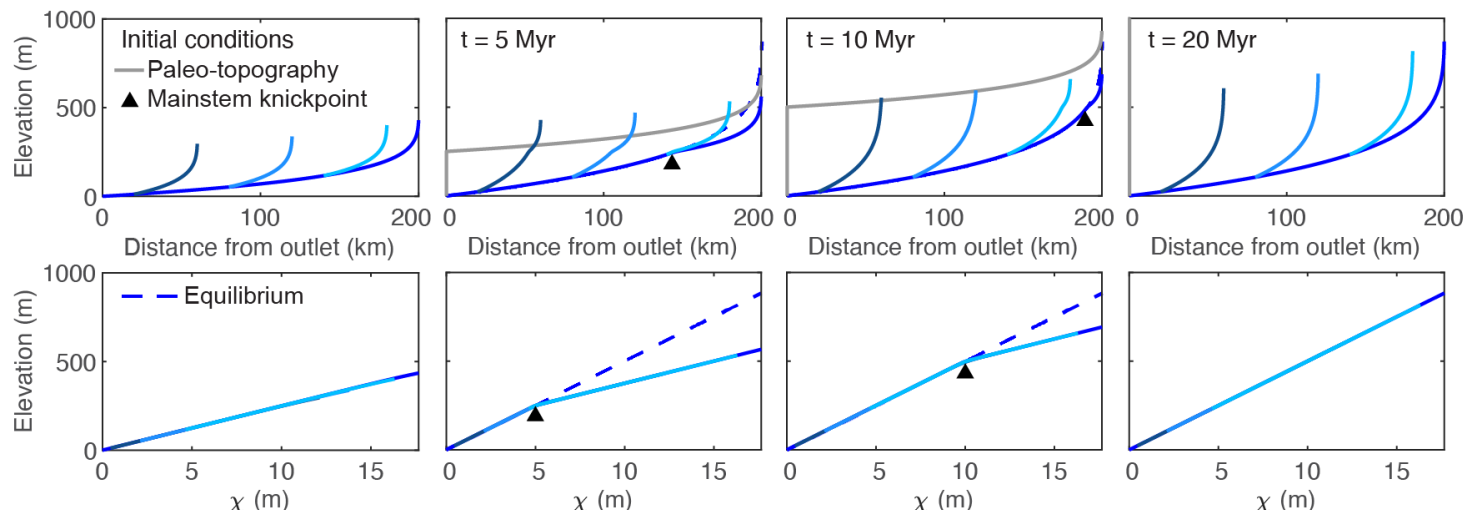

Distance from outlet $(\mathrm{km})$

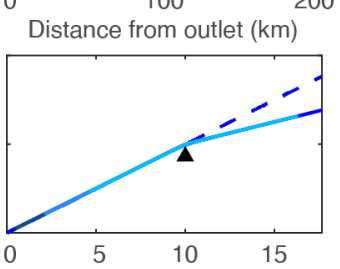

Distance from outlet $(\mathrm{km})$
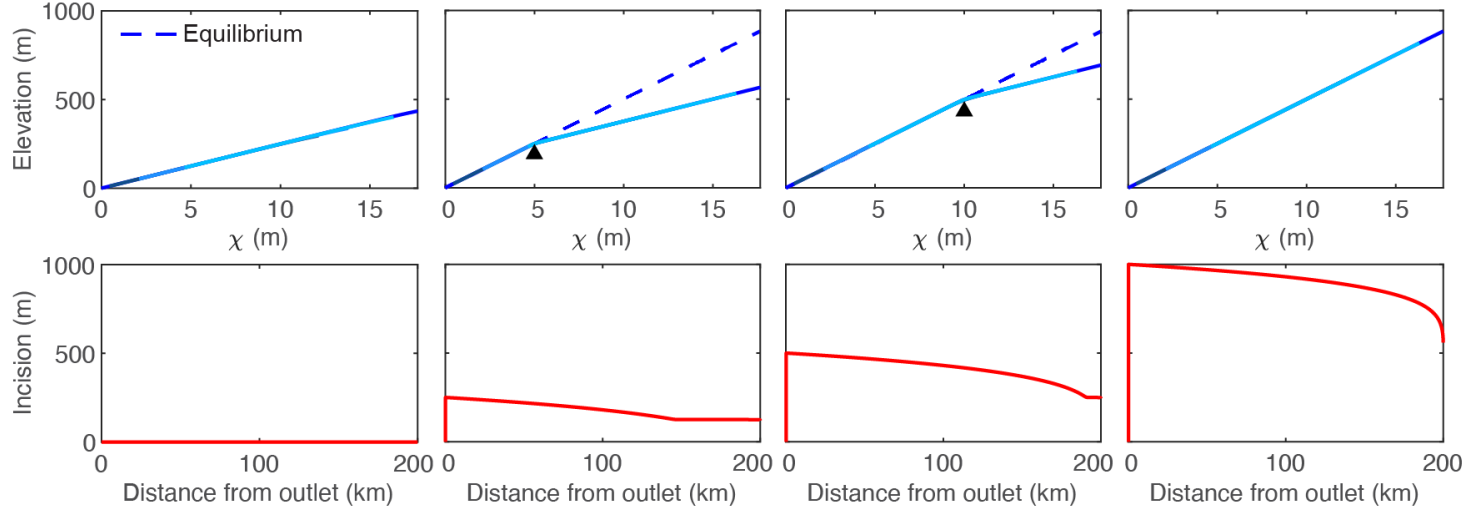

Figure S3. Results from multiple timesteps for simulation of a step decrease in erodibility, $K$. The initial condition is a river profile equilibrated to a uniform background uplift rate of $50 \mathrm{mMyr}^{-1}$ and a erodibility of $K=2 \times 10^{-6} \mathrm{~m}^{0.1} \mathrm{yr}^{-1}$, which is then lowered to $K=1 \times 10^{-6} \mathrm{~m}^{0.1} \mathrm{yr}^{-1}$. An increase in uplift rate from 25 to $50 \mathrm{mMyr}^{-1}$ produces the same profile form. Line color, basic description of plots filling each row, and network structure are the same as described in Fig. 1. 
(a)

Instantaneous beheading of mainstem river at $\mathrm{t}=0 \mathrm{Myr}$. Steady uniform background uplift rate of $50 \mathrm{mMyr}^{-1} . n=2 / 3$.
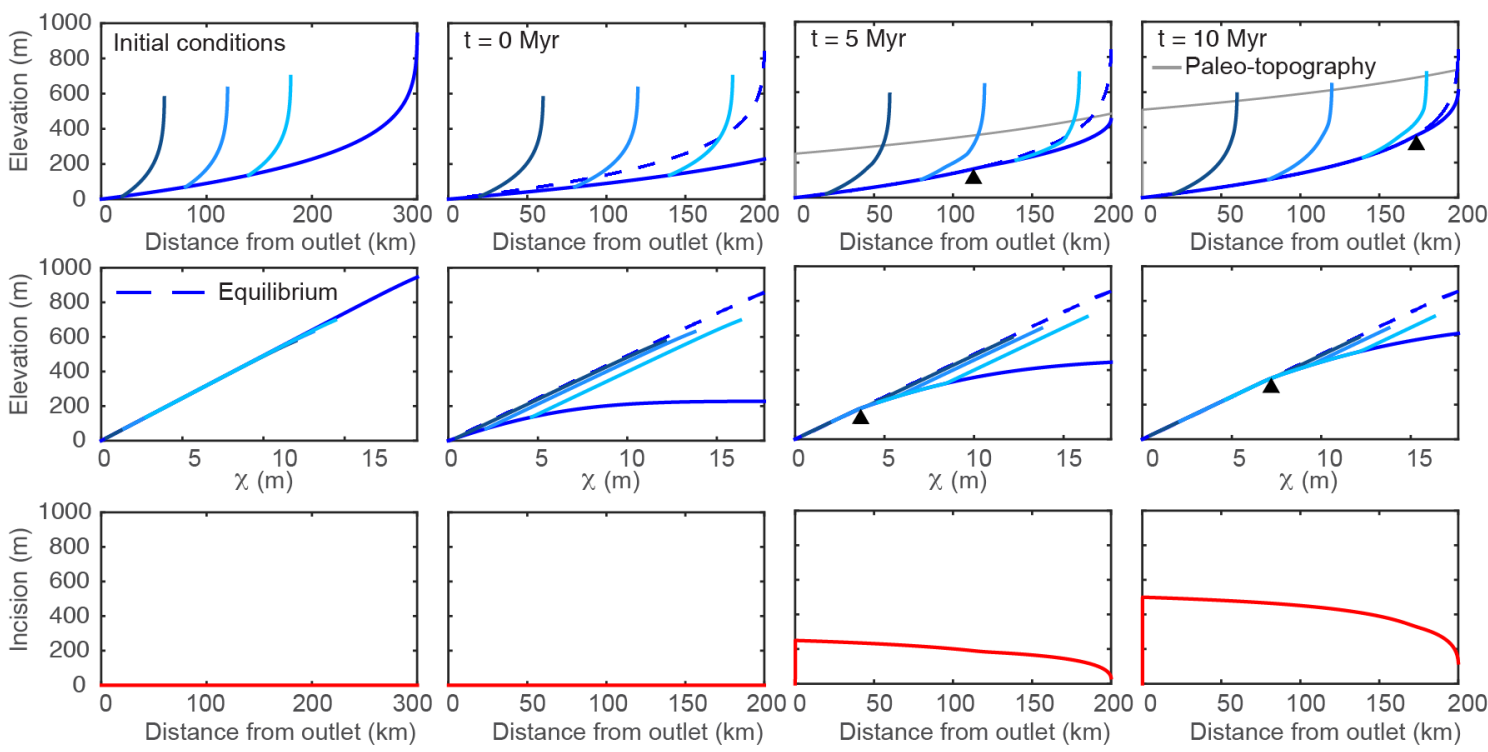

(b)

Instantaneous tilt uplift of $1 \mathrm{~km}$ at $\mathrm{t}=0 \mathrm{Myr}$. Steady uniform background uplift rate of $50 \mathrm{mMyr}^{-1} . n=2 / 3$.
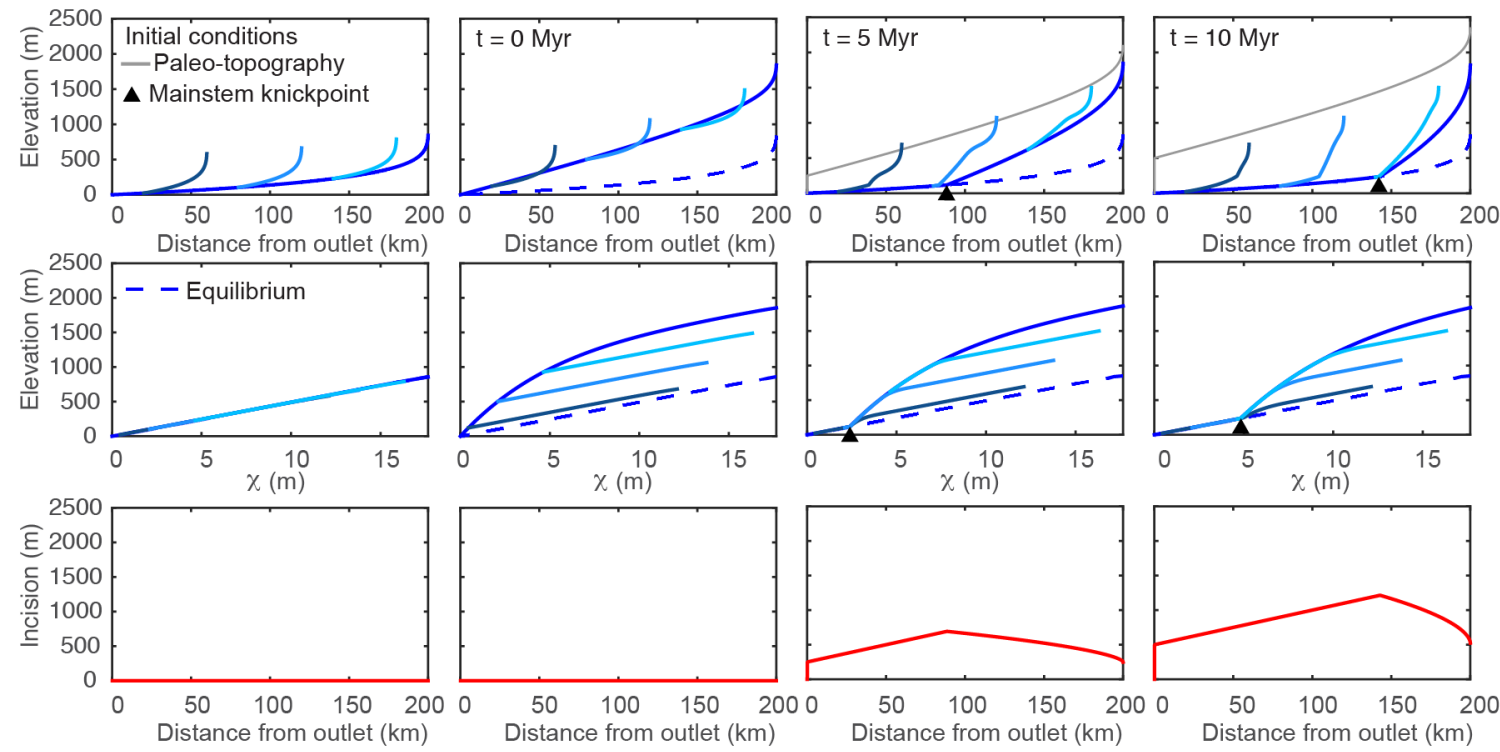

Figure S4. Results from 1-D simulations of equilibrated river network subject to various perturbations that move profiles away from equilibrium. Simulations are analogous to those presented in Fig. 3 but were run with $n=2 / 3$. We used the same concavity, $\theta=0.45$, as other simulations but adjusted $K$ to $3.7 \times 10^{-6} \mathrm{~m}^{0.4} \mathrm{yr}^{-1}$ such that steady-state fluvial relief remained the same between all simulations run with $n=1$ and $n=2 / 3$. Results from multiple timesteps for simulation of instantaneous truncation of a $300 \mathrm{~km}$ long river to from a $200 \mathrm{~km}$ long river (a); and instantaneous tilting at $t=0 \mathrm{Myr}$ with tilt axis at the river mouth, perpendicular to the main stem, and $1 \mathrm{~km}$ maximum uplift at the channel head (b). Line color, basic description of plots filling each row, and network structure are the same as described in Fig. 1. 
(a)

Instantaneous beheading of mainstem river at $\mathrm{t}=0 \mathrm{Myr}$. Steady uniform background uplift rate of $50 \mathrm{mMyr} \mathrm{r}^{-1} . n=5 / 3$.
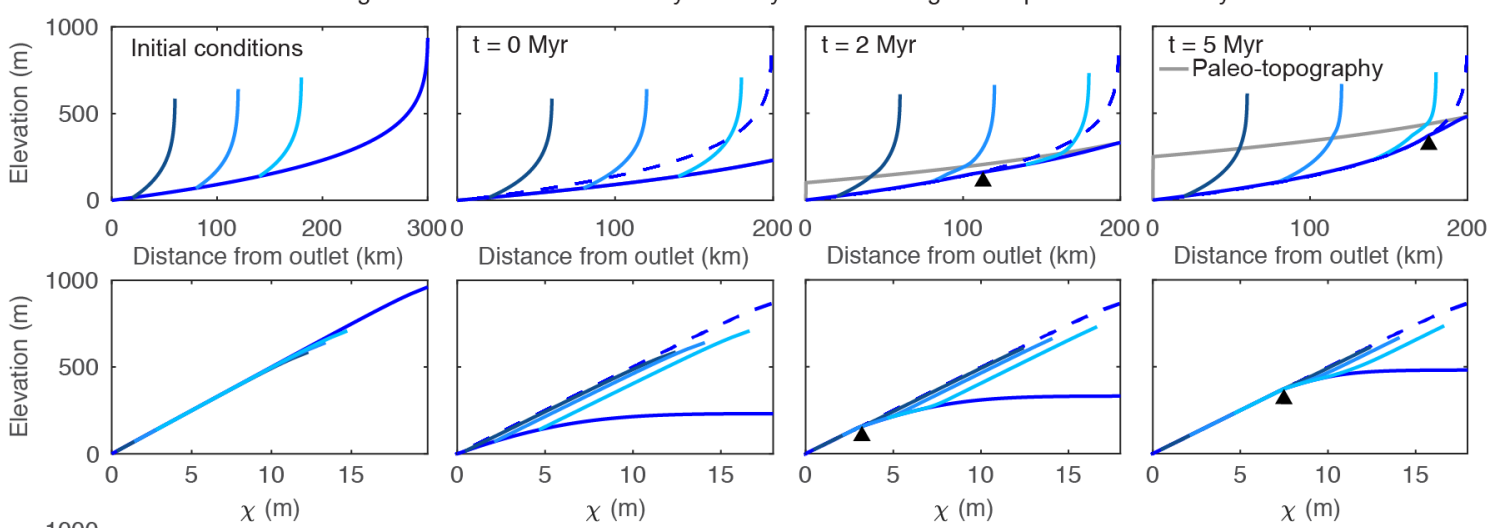

Distance from outlet $(\mathrm{km})$
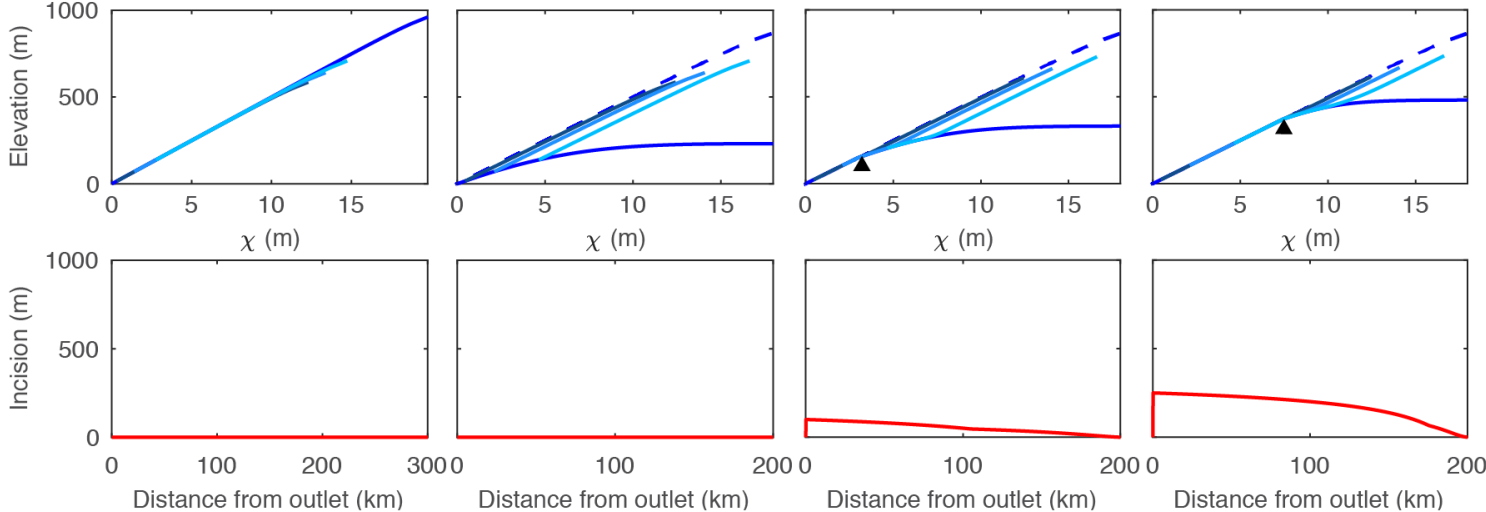

(b)
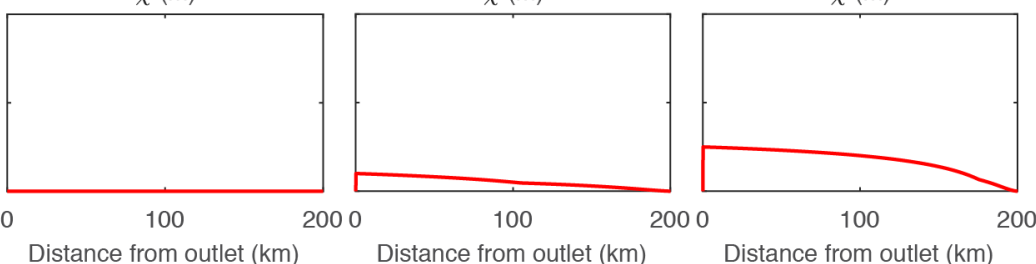

Instantaneous tilt uplift of $1 \mathrm{~km}$ at $\mathrm{t}=0 \mathrm{Myr}$. Steady uniform background uplift rate of $50 \mathrm{mMyr}^{-1} . n=5 / 3$.
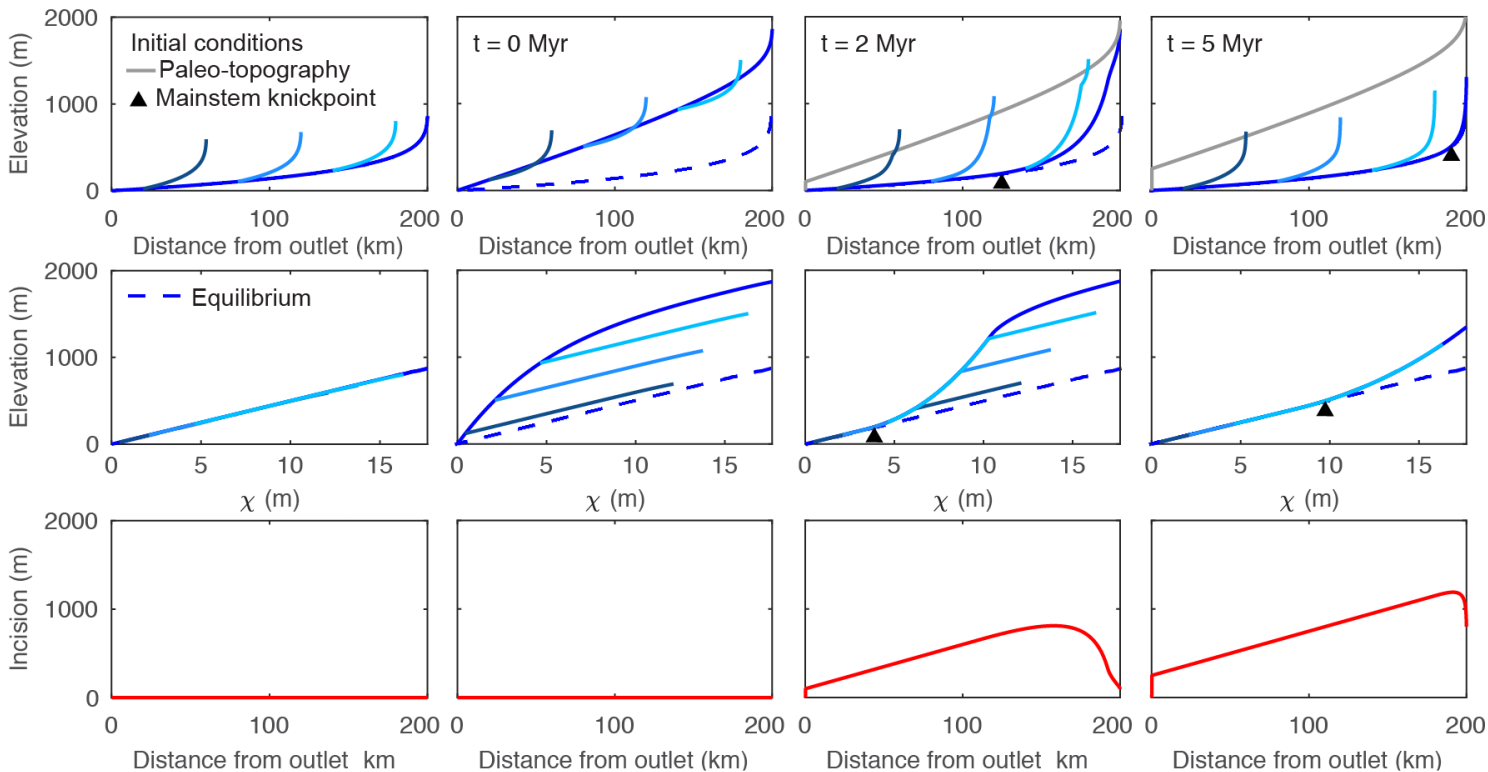

Figure S5. Results from 1-D simulations of equilibrated river network subject to various perturbations that move profiles away from equilibrium. Simulations are analogous to those presented in Fig. 3 but were run with $n=5 / 3$. We used the same concavity, $\theta=0.45$, as other simulations but adjusted $K$ to $7.4 \times 10^{-8} \mathrm{~m}^{-0.5} \mathrm{yr}^{-1}$ such that steady-state fluvial relief remained the same between all simulations run with $n=1$ and $n=5 / 3$. Results from multiple timesteps for simulation of instantaneous truncation of a $300 \mathrm{~km}$ long river to from a $200 \mathrm{~km}$ long river (a); and instantaneous tilting at $t=0 \mathrm{Myr}$ with tilt axis at the river mouth, perpendicular to the main stem, and $1 \mathrm{~km}$ maximum uplift at the channel head (b). Line color, basic description of plots filling each row, and network structure are the same as described in Fig. 1 . 
Instantaneous back-tilt of $200 \mathrm{~m}$ at the river outlet at $\mathrm{t}=0$ Myr. Steady uniform background uplift rate of $50 \mathrm{mMyr}^{-1}$.
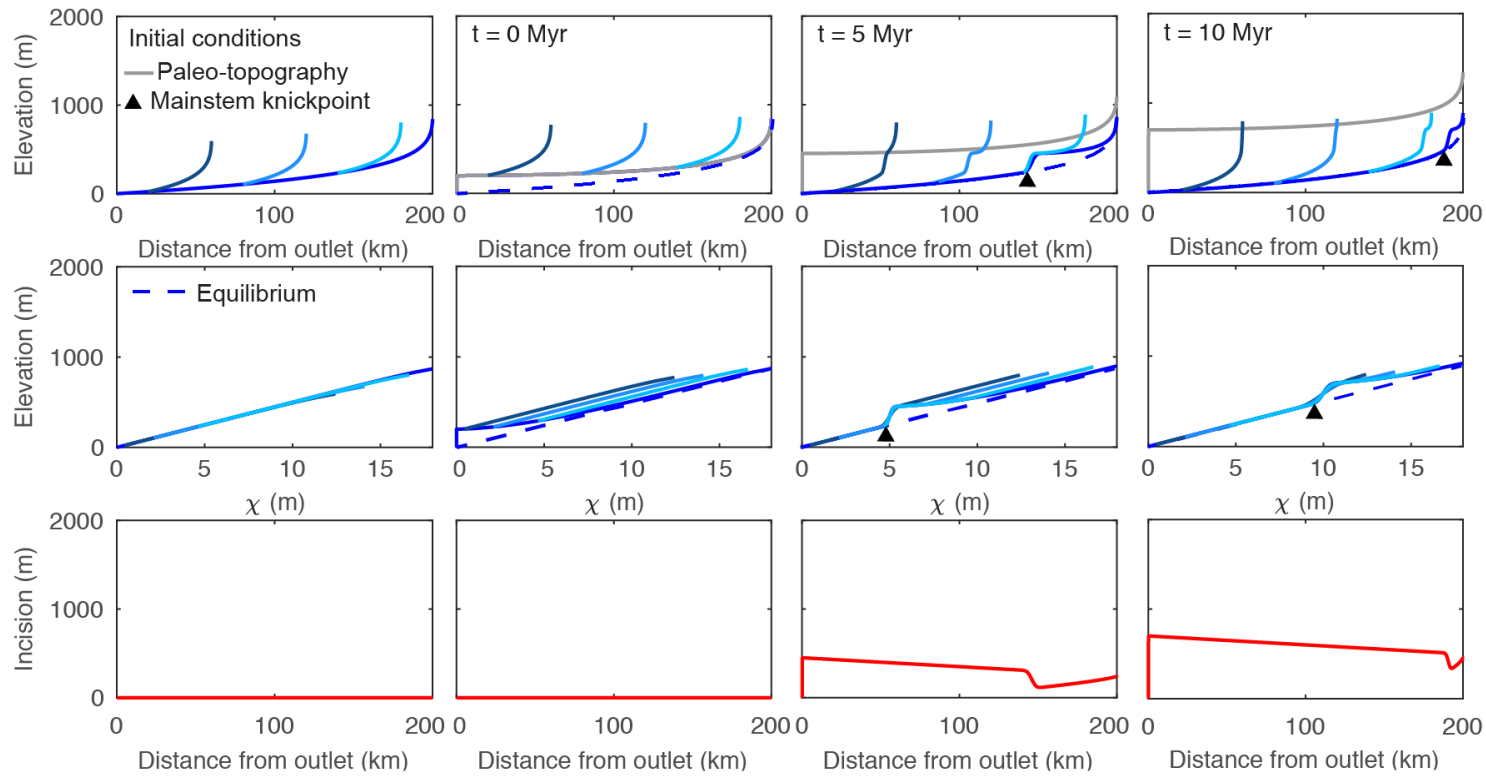

Figure S6. Results from 1-D simulations of equilibrated river network subject to various perturbations that move profiles away from equilibrium. Results from multiple timesteps for simulation of instantaneous back tilt of $1 \mathrm{~km}$ about an axis located on the mainstem and perpendicular to the tributaries. Line color, basic description of plots filling each row, and network structure are the same as described in Fig. 1. 
(a)
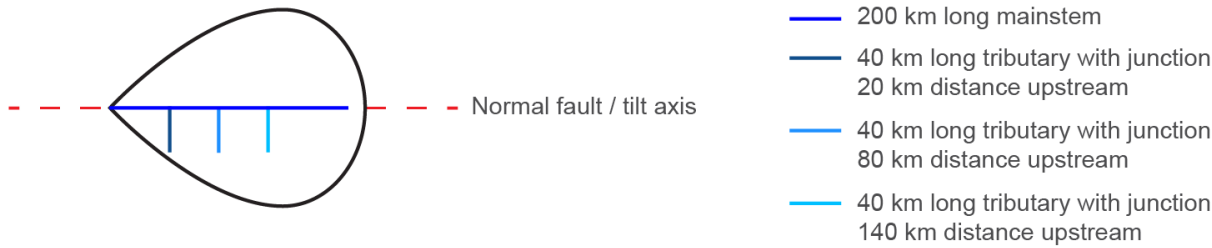

(b) Instantaneous tilt uplift of $800 \mathrm{~m}$ at $\mathrm{t}=0 \mathrm{Myr}$ about an axis located on the mainstem and perpendicular to the tributaries. Steady uniform background uplift rate of $50 \mathrm{~m} / \mathrm{Myr}$.
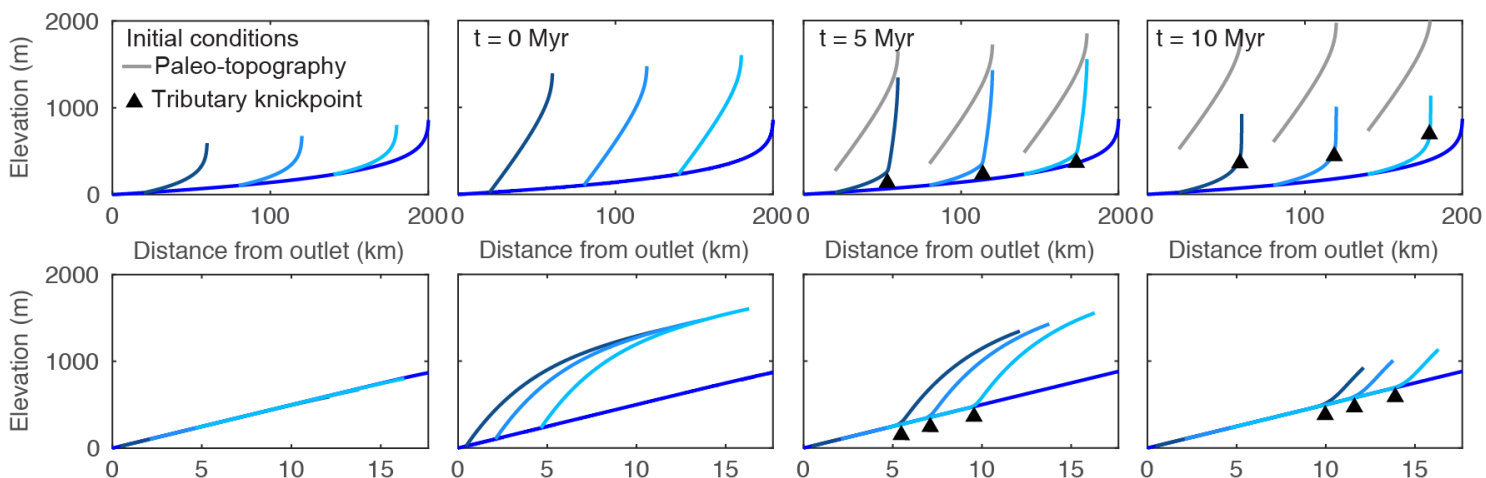

Distance from outlet $(\mathrm{km})$
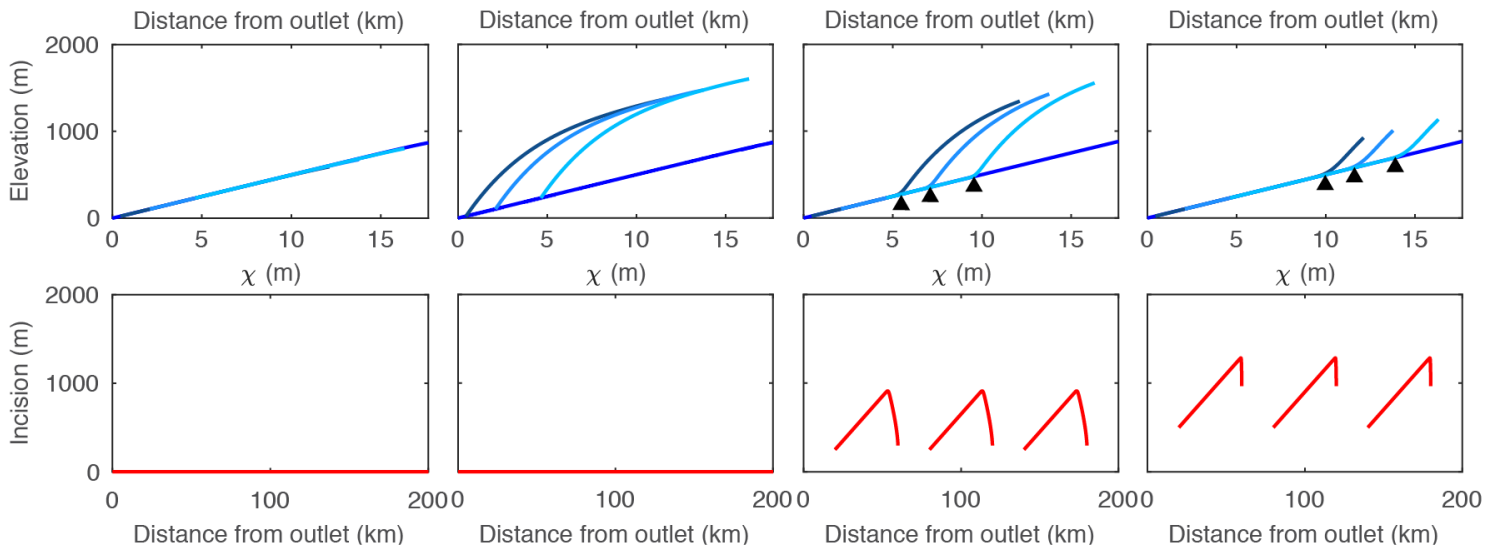

Figure S7. Results from 1-D simulations of equilibrated river network subject to various perturbations that move profiles away from equilibrium. (a) 1-D model setup for simulation of instantaneous lateral tilt of a drainage basin. (b) Results from multiple timesteps for simulation of instantaneous lateral tilt of $1 \mathrm{~km}$ about an axis located on the mainstem and perpendicular to the tributaries. Basic description of plots filling each row are the same as described in Fig. 1. 

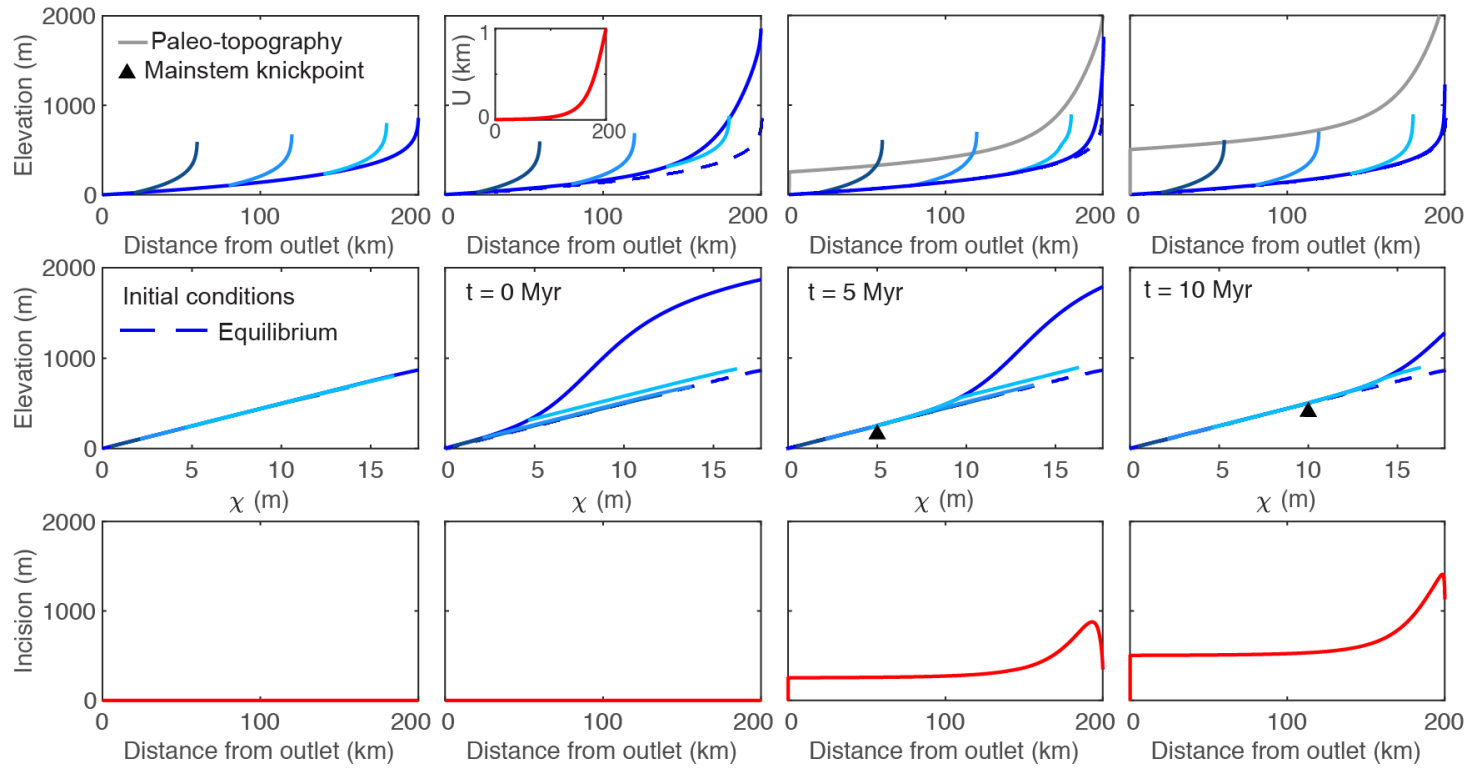

Figure S8. Results from 1-D simulations of equilibrated river network subject to various perturbations that move profiles away from equilibrium. Results from multiple timesteps for simulation of instantaneous forward (toward the outlet) tilt of $1 \mathrm{~km}$ at the crest but with non-uniform uplift that deviates from perfect rigid-block forward tilting. The inset in the top row shows the uplift field that was set using results from a single-dislocation model with slip-boundary conditions in an elastic half-space as explained by Martel et al. (2014). Basic description of plots filling each row are the same as described in Fig. 1. 
Continuous rigid-block forward tilting of $1 \mathrm{~km}$ at the crest over $5 \mathrm{Myr}$ with band of more erodible rock at 70-120 km upstream.

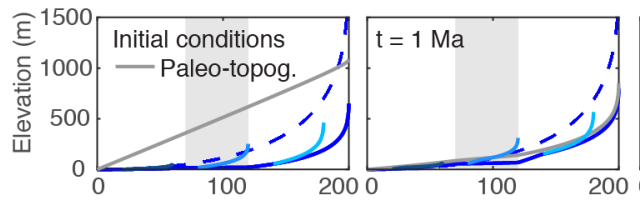

Dist. from outlet $(\mathrm{km}) \quad$ Dist. from outlet $(\mathrm{km})$

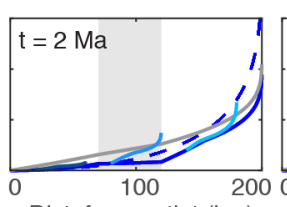

Dist. from outlet $(\mathrm{km})$

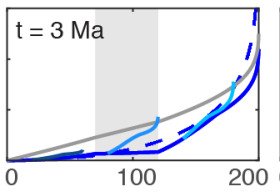

Dist. from outlet $(\mathrm{km})$
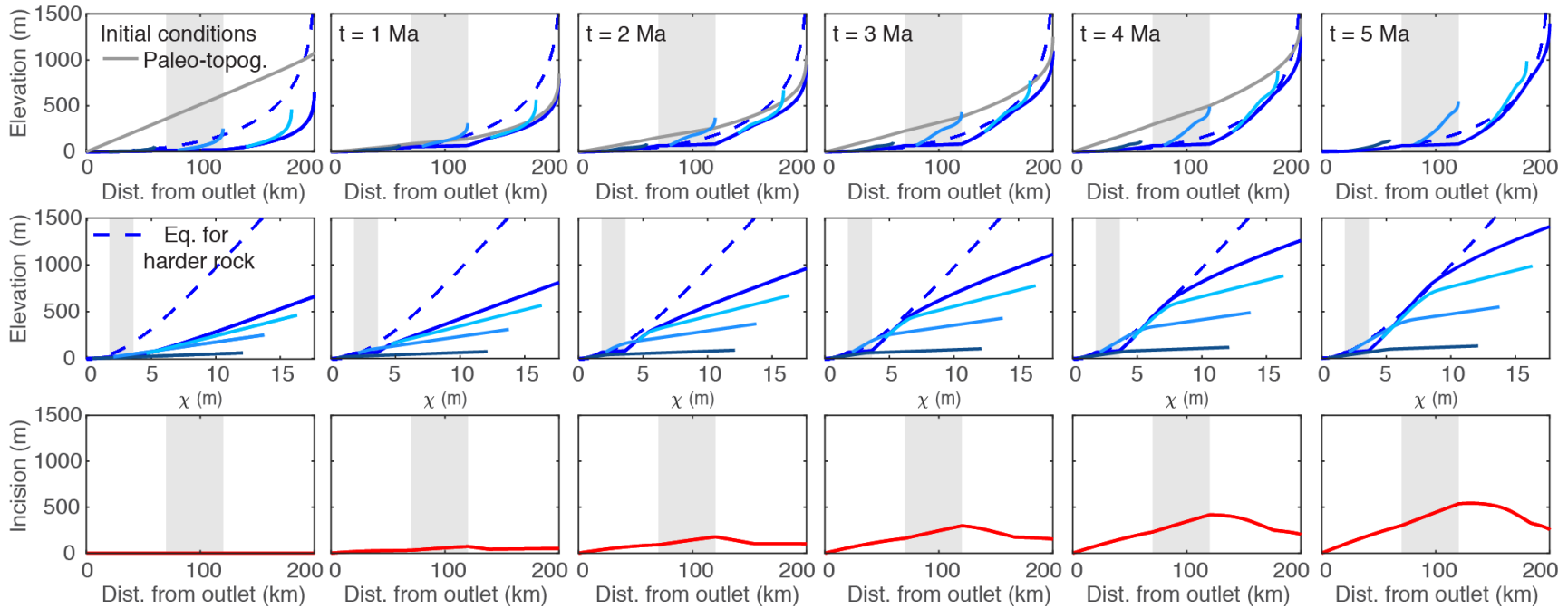

Figure S9. Results from a 1-D simulation of an equilibrated river network subject to continuous rigid-block forward tilting of $200 \mathrm{mMyr}^{-1}$ at the channel head with a band of more erodible rock at 70-120 km upstream of the mountain front but with only the mainstem traversing the heterogeneous lithology. Line color, basic description of plots filling each row, and network structure are the same as described in Fig. 1. $K=1 \times 10^{-6} \mathrm{~m}^{0.1} \mathrm{yr}^{-1}$ was used for the majority of the river profile aside from a $50 \mathrm{~km}$ vertical band (shown in grey) which was assigned a $K$ value of $1 \times 10^{-5} \mathrm{~m}^{0.1} \mathrm{yr}^{-1}$. 
(a)

Initial river equilibrated to $U=50 \mathrm{mMyr}^{-1}$ and $K=1 \times 10^{-6}$ with band of $K=1 \times 10^{-5} \mathrm{~m}^{1-2 \mathrm{~m}} \mathrm{yr}^{-1}$; subject to $1^{\circ}$ tilt
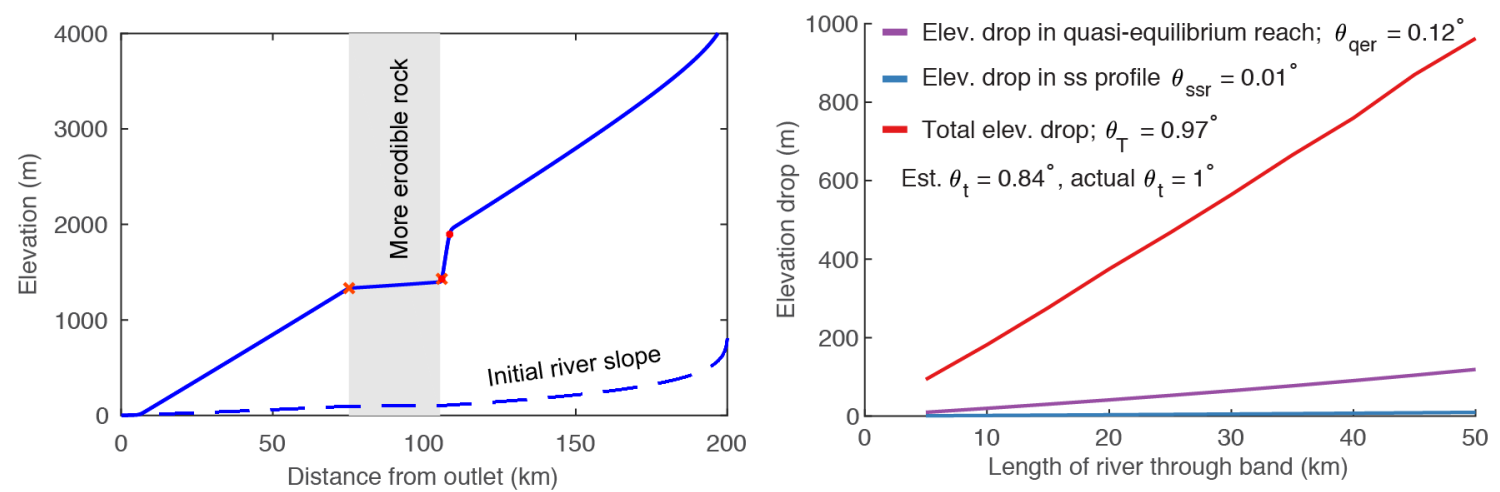

(b)

Initial river equilibrated to $U=50 \mathrm{mMyr}^{-1}$ and $K=1 \times 10^{-6}$ with band of $K=2 \times 10^{-6} \mathrm{~m}^{1-2 \mathrm{~m}} \mathrm{yr}$; subject to $0.5^{\circ}$ tilt
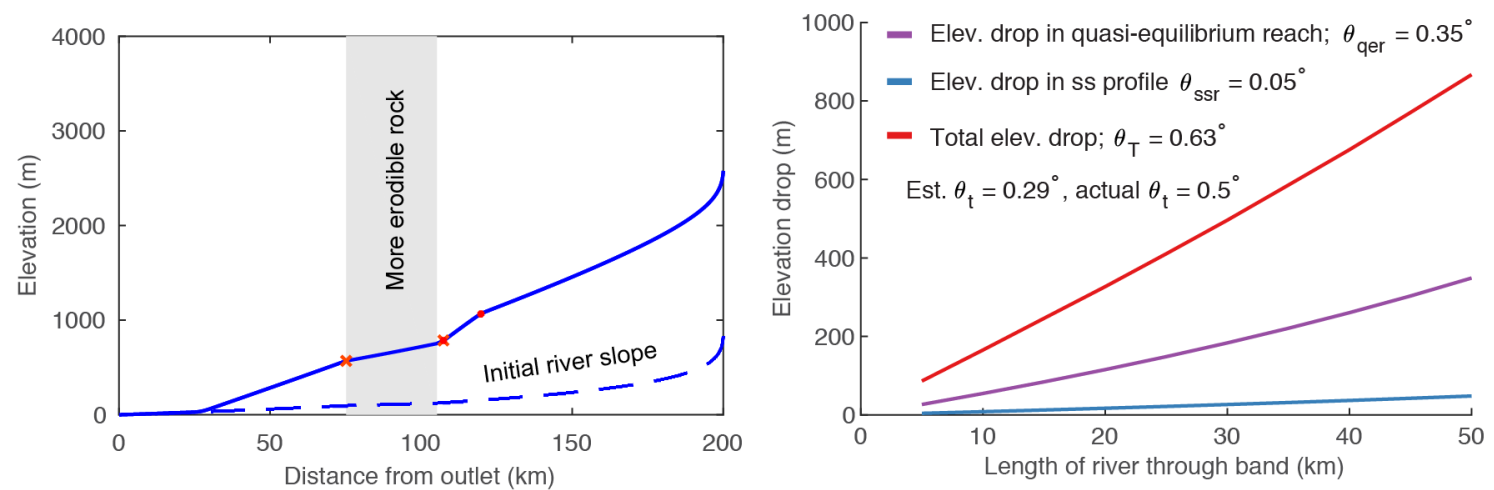

Figure S10. Measurements of tilt angle from the geometry of mid-profile knickzones in a 1-D model of instantaneous tilt of $1^{\circ}$ at $t=0$ with bands of soft rock of increasing width at $75 \mathrm{~km}$ upstream in a $200 \mathrm{~km}$ river. Erodibility in the band of soft rock is a factor of two greater $\left(K=2 \times 10^{-6} \mathrm{~m}^{0.1} \mathrm{yr}^{-1}\right)$ than the rest of profile $\left(K=1 \times 10^{-6} \mathrm{~m}^{0.1} \mathrm{yr}^{-1}\right)$. Initial river profile is equilibrated to $K=1 \times 10^{-6} \mathrm{~m}^{0.1} \mathrm{yr}^{-1}$. (a) and (b) Examples of river profiles at the end of simulations for the case in which the base of the knickzone is at the upper rock-type contact (a) as compared to the case in which the base of the knickzone has propagated $5 \mathrm{~km}$ upstream of the upper rock-type contact (b). In each simulation, the knickzone is identified using peaks and troughs in curvature of the river profile. (c) and (d) Measurements of knickzone height as a function of length of reach with more erodible rock. Simulations were stopped and measurements of knickzone height were taken when the base of the knickzone was at the upper lithologic contact (c) and $5 \mathrm{~km}$ upstream of upper contact (d). Tilt angle is estimated using linear regression of knickzone height measurements with the intercept forced through the origin. 

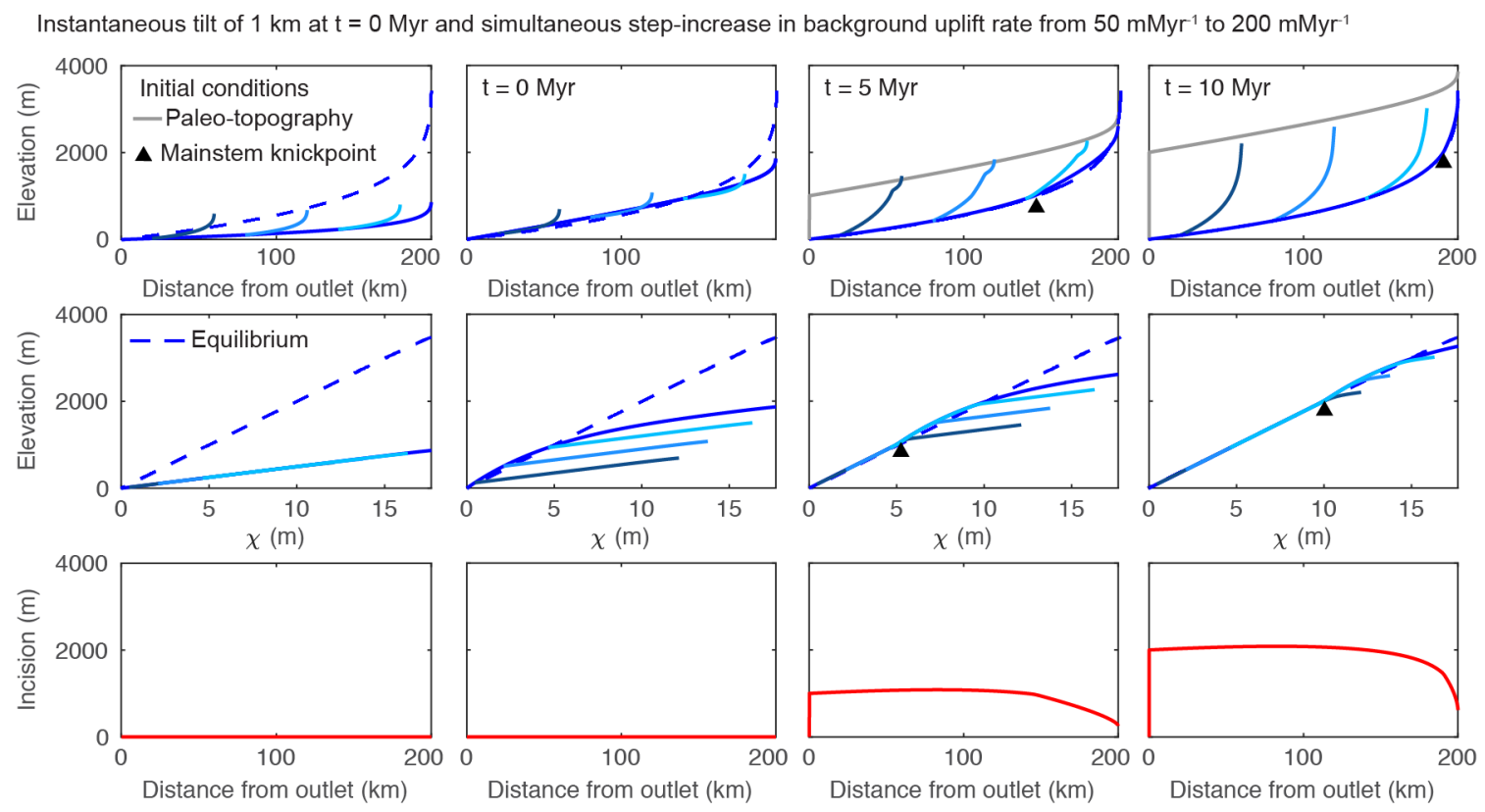

Distance from outlet $(\mathrm{km})$
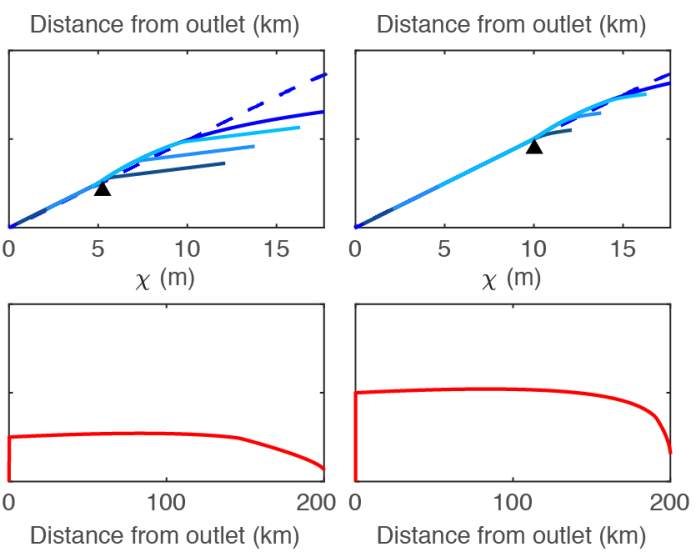

Figure S11. Results from multiple timesteps for simulation of instantaneous tilting at $t=0 \mathrm{Myr}$ with a simultaneous step-increase in background uplift rate from $50 \mathrm{mMyr}^{-1}$ to $200 \mathrm{mMyr}^{-1}$. The initial condition is a river profile equilibrated to a uniform background uplift rate of $50 \mathrm{mMyr}^{-1}$ and a erodibility of $K=1 \times 10^{-6} \mathrm{~m}^{0.1} \mathrm{yr}^{-1}$. Line color, basic description of plots filling each row, and network structure are the same as described in Fig. 1. 


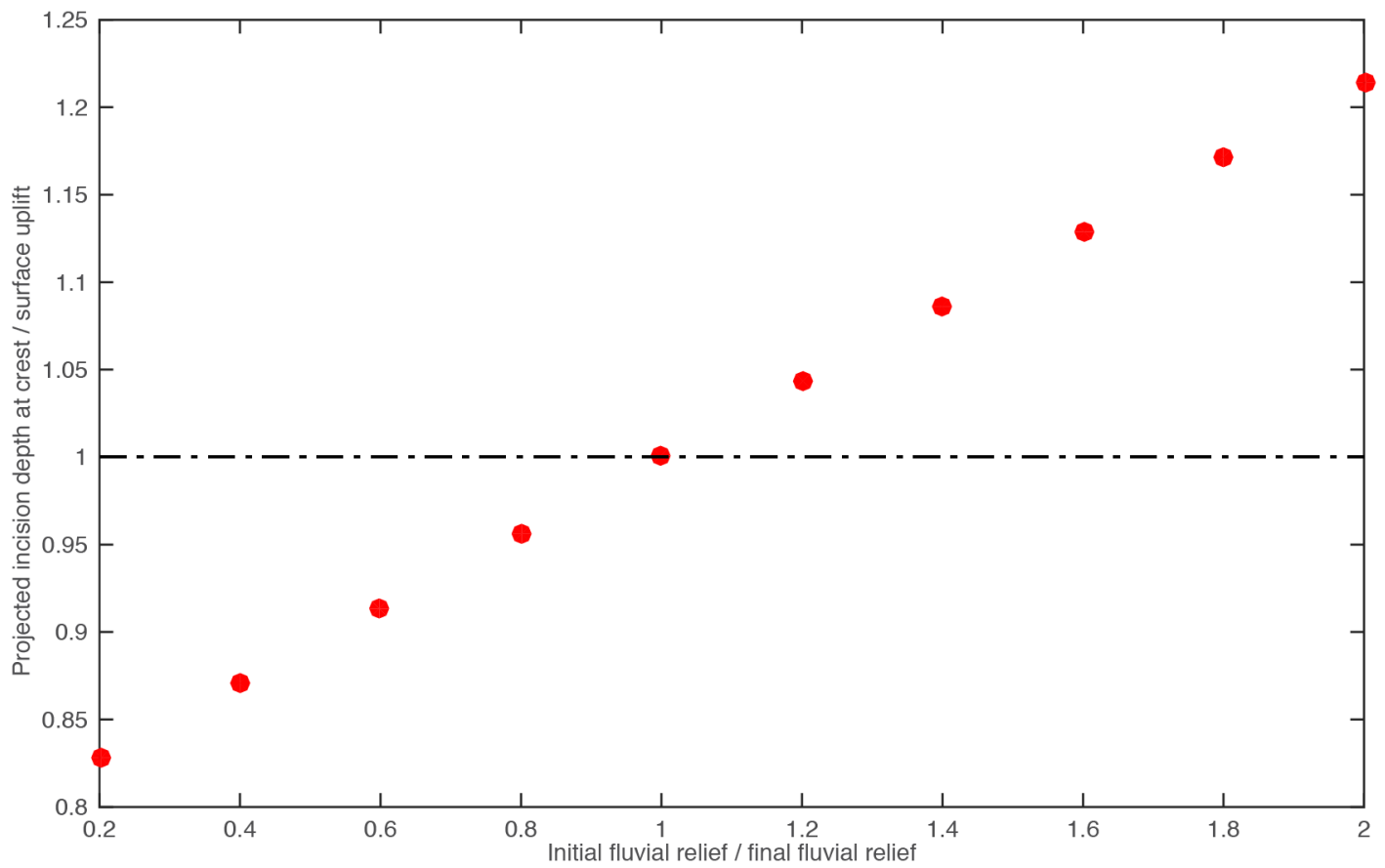

Figure S12. Estimates of surface uplift made from incision depth below paleotopography markers from 1-D simulations of a rapid pulse of nonuniform uplift due to tilting accompanied by a step-change in fluvial relief. 
(a)

Instantaneous uniform uplift of $1 \mathrm{~km}$ at $\mathrm{t}=0 \mathrm{Myr}$ and instantaneous tilt of $1 \mathrm{~km}$ at crest at $\mathrm{t}=5 \mathrm{Myr}$.

Steady uniform background uplift rate of $50 \mathrm{mMyr}^{-1}$.
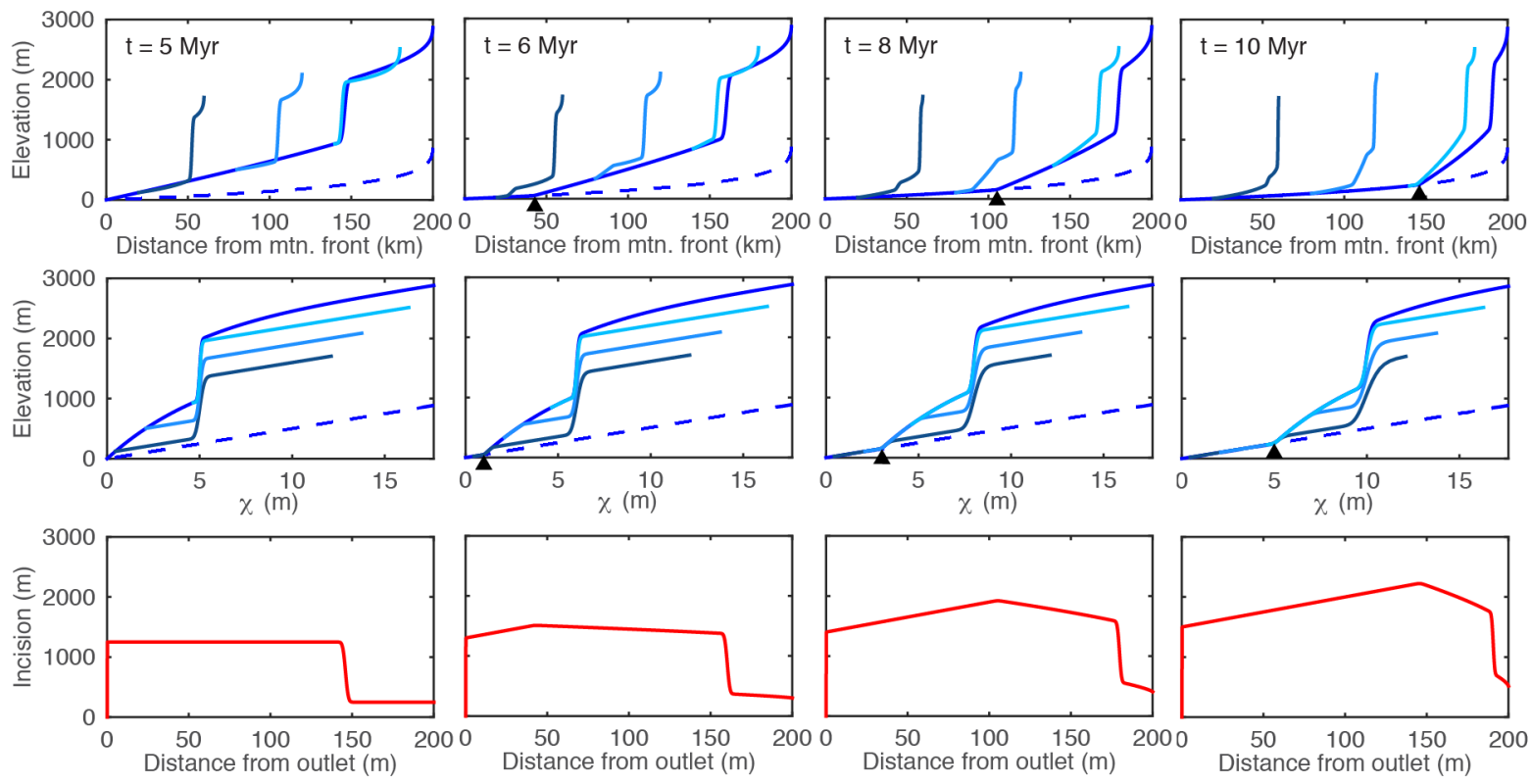

(b)

Instantaneous tilt uplift of $1 \mathrm{~km}$ at $\mathrm{t}=0 \mathrm{Myr}$ and again at $\mathrm{t}=5 \mathrm{Myr}$. Steady uniform background uplift rate of $50 \mathrm{mMyr}^{-1}$.
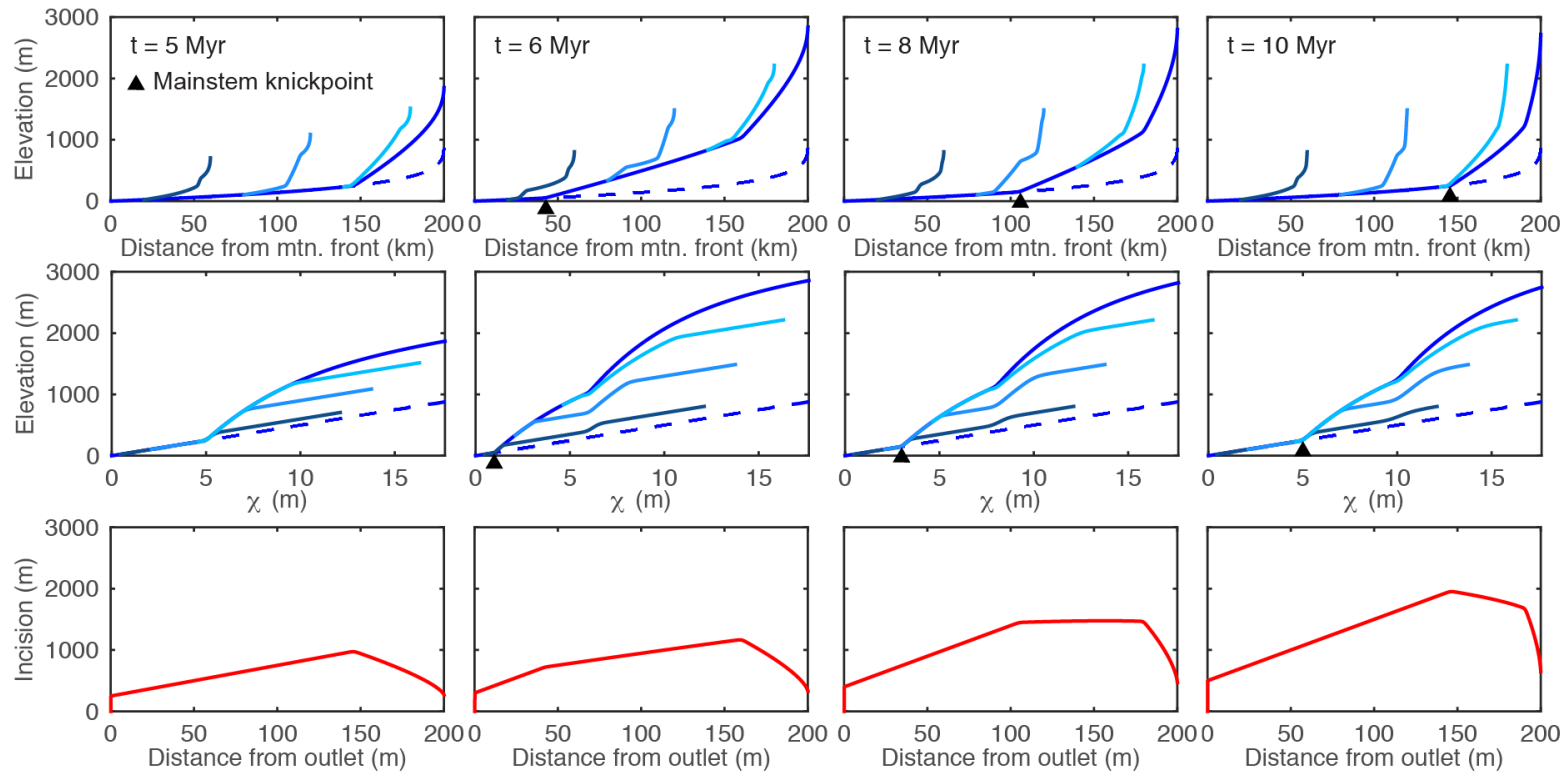

Figure S13. Results from 1-D river simulations of rapid nonuniform uplift due to tilting with disequilibrium initial conditions. (a) Uniform pulse of uplift of $1 \mathrm{~km}$ at $t=0 \mathrm{Myr}$ and instantaneous tilt of $1 \mathrm{~km}$ at the crest at $t=5 \mathrm{Myr}$. (b) Instantaneous tilt of $1 \mathrm{~km}$ at $t=0 \mathrm{Myr}$ and an instantaneous tilt of $1 \mathrm{~km}$ at $t=5 \mathrm{Myr}$. Line color, basic description of plots filling each row, and network structure are the same as described in Fig. 1. 
(a)
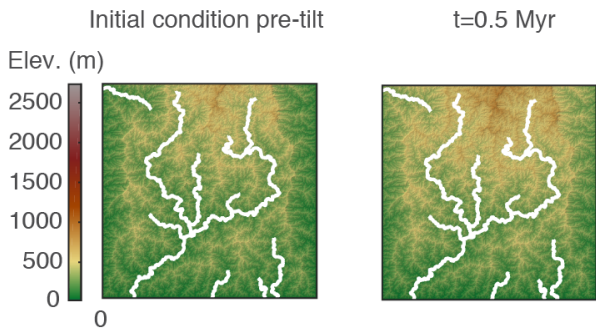

(b)

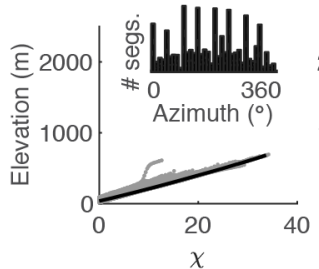

(c)

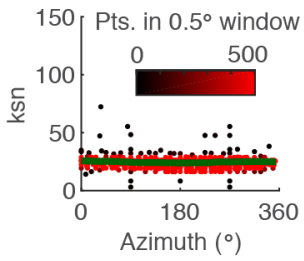

(d)

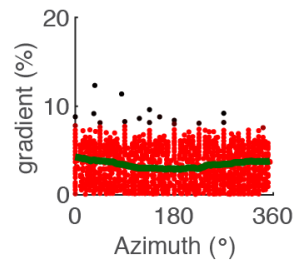

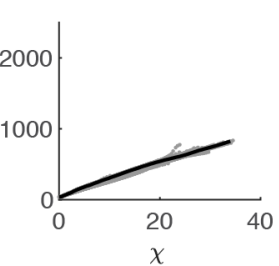
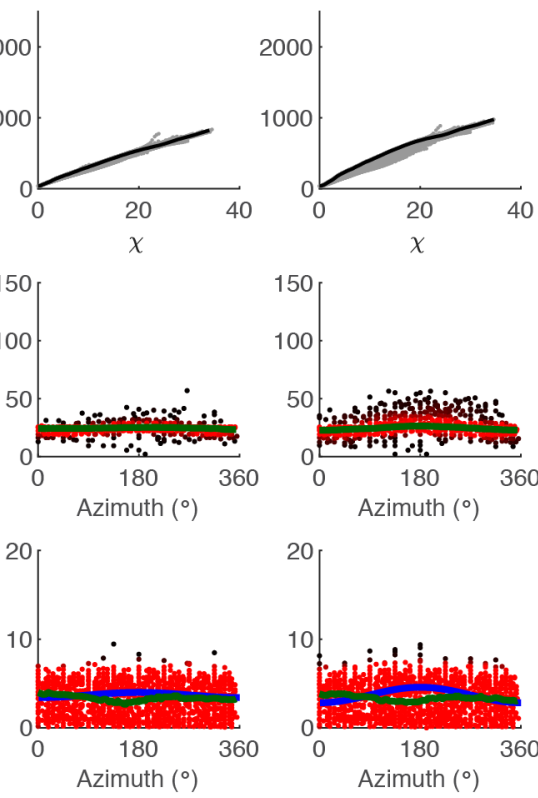
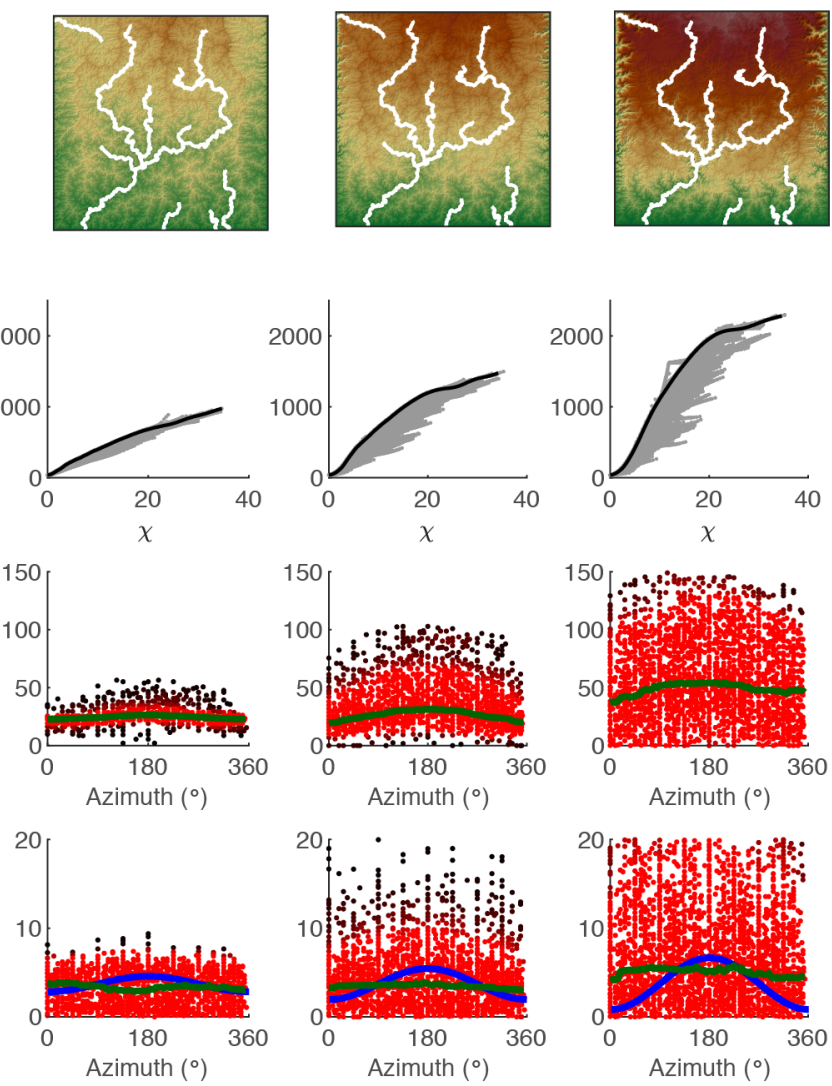

- Running median in $10^{\circ}$ window

- $y=$ magnitude* $\cos ($ azimuth-direction)+paleogradient

Figure S14. Evidence of tilt in relationships between azimuth and gradient and $k_{s n}$ of $3 \mathrm{~km}$ long segments of river networks generated in a 2-D simulation of a $0.5^{\circ}$ tilt that occurs over 3 Myr. (a) DEMs with mainstems of the stream network shown in white. (b) $\chi$ plots for entire river network with points on the mainstem shown in black and all tributary points shown in gray. (c) Plot of segment $k_{s n}$ against azimuth with point color indicating density of points within $0.5^{\circ}$ azimuth window. (d) Plot of segment gradient against azimuth colors as in $\mathbf{c}$. Inset in $\mathbf{b}$ shows the distribution of azimuth of $3 \mathrm{~km}$ stream segments demonstrating that the distribution of segments is approximately uniform pre-tilt. Blue line shows cosine function with known parameters of tilt perturbation in the simulation. Green line shows $10^{\circ}$ wide moving-window medians. 

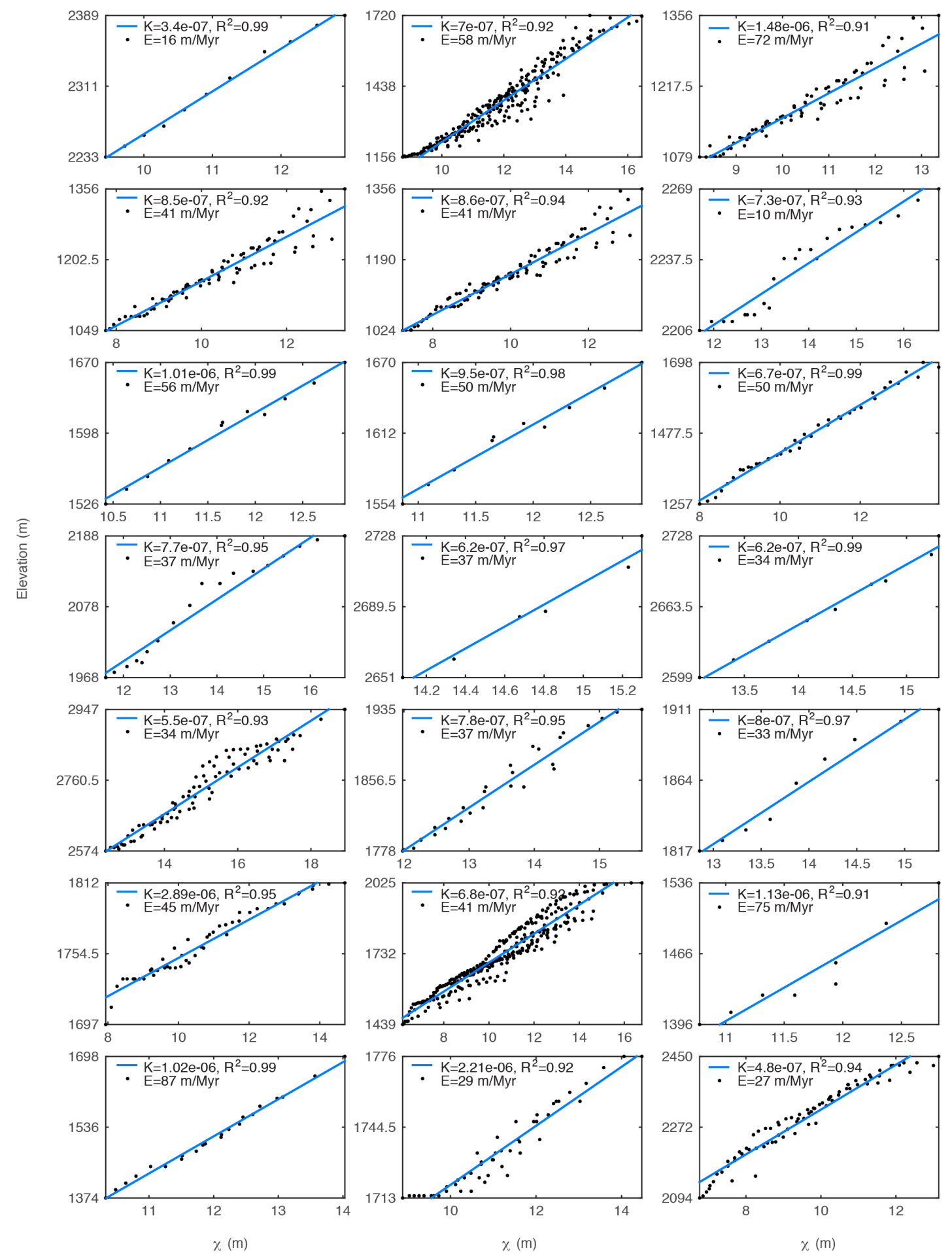

Figure S15. $\chi$ plots for stable upland basins underlain by the Sierra batholith that were used to back-calculate $K$ from $k_{s n}$ (the slope of the regression line) using published catchment-average erosion rates (Callahan et al., 2019). 
(a)

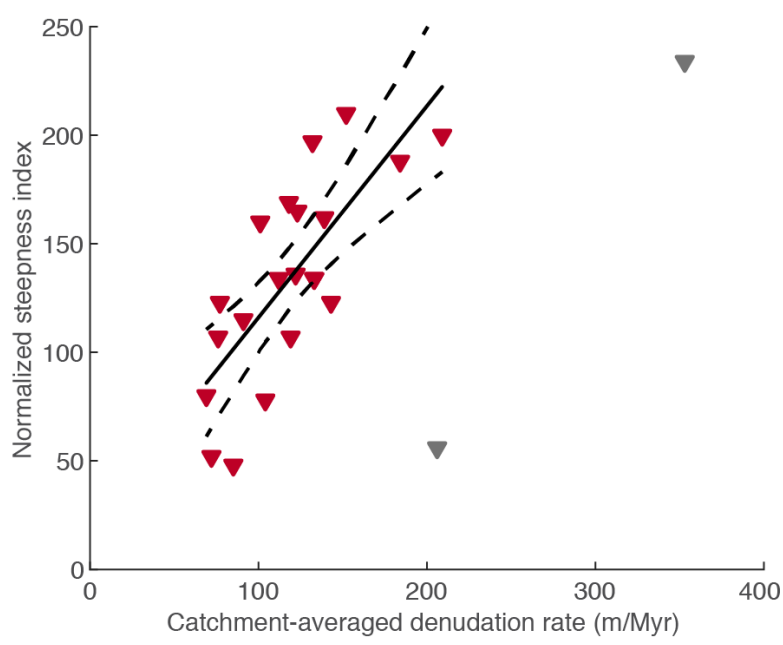

Catchment-averaged denudation rate (m/Myr) (b)

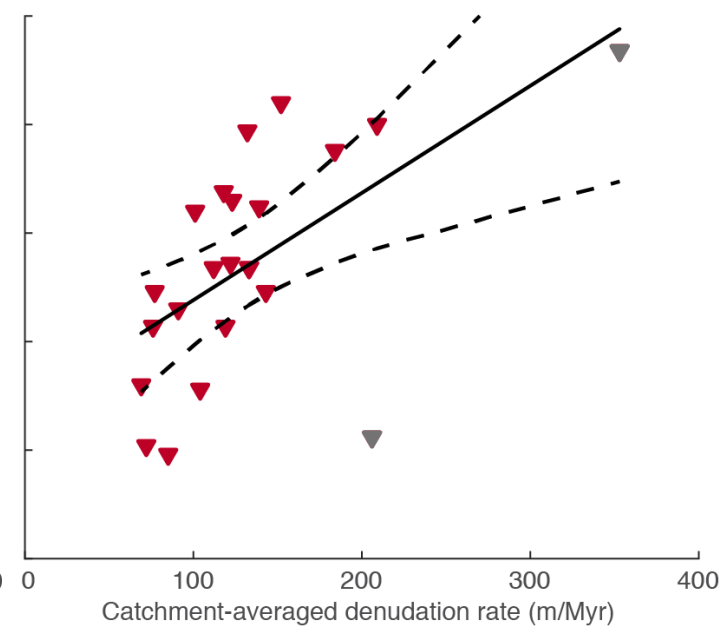

Field measurements Outlier field measurements

$K=2 e-06(8 e-07-3.3 e-06), R^{2}=0.35$

Figure S16. ${ }^{10}$ Be-based catchment-averaged denudation rates plotted against $k_{s n}$ values from sample streams adapted from Rossi et al. (2017). Solid black lines shows best-fit linear regression and dashed black lines show the 95confidence intervals on the best-fit lines, from which the ranges in $K$ were calculated. In (a), two outlier points are excluded from the regression (grey triangles) and in (b) these points are included. 

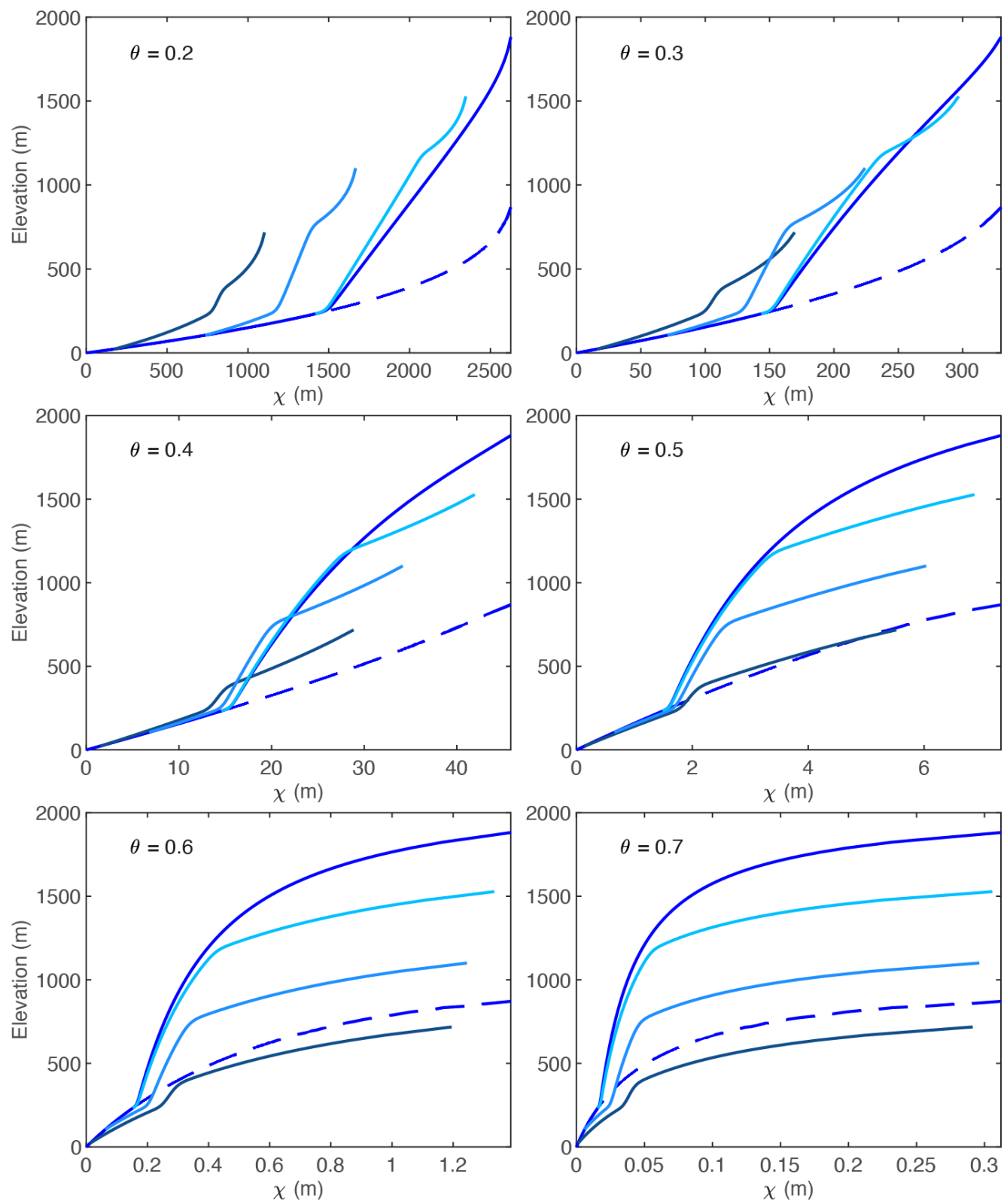

Figure S17. $\chi$ plots for results at $t=5 \mathrm{Myr}$ from 1-D simulation of instantaneous rigid-block forward tilting of $1 \mathrm{~km}$ at the crest at $t=0 \mathrm{Myr}$. Plots show $\chi$ calculated for a range of $\theta$ values that bracket the correct $\theta(0.45)$ to demonstrate how using an incorrect $\theta_{\text {ref }}$ when calculating $\chi$ impacts geomorphic signatures of the transient fluvial response to tilting. Although both the position of tributaries relative to the mainstem in the $\chi$ plot and the curvature of both the mainstem and tributaries upstream of knickpoints changes with concavity, the positive curvature slope-break knickpoint in the mainstem and changes in curvature associated with the upstream and downstream ends of tributary knickzones are consistent through all concavity values shown. 